\title{
HUBUNGAN PENGETAHUAN IBU HAMIL DENGAN KEIKUTSERTAAN KELAS IBU HAMIL DI WILAYAH KERJA PUSKESMAS JENGGOT KOTA PEKALONGAN
}

\author{
Ida Baroroh ${ }^{1}$, Miftachul Jannah ${ }^{2}$, Pedvin Ratna Meikawati ${ }^{3}$ \\ Email : idamidoren@gmail.com \\ 1,2,3 Akademi Kebidanan Harapan Ibu Pekalongan, Jl. Sriwijaya No. 7 Kota Pekalongan. \\ Telp ( 085102998866$)$
}

\begin{abstract}
Abstrak
Kehamilan dan persalinan adalah suatu hal yang alami akan tetapi bukan berarti tanpa resiko, masalah kehamilan dan persalinan adalah penyumbang terbesar Angka Kematian Ibu dan Angka Kematian Bayi. Salah satu terobosan untuk meningkatkan pengetahuan ibu hamil dengan melalui kelas ibu hamil, namun demikian banyak ibu yang belum berpartisipasi dalam mengikuti kelas ibu hamil. Penelitian ini bertujuan: 1) Mengetahui pengetahuan ibu hamil; 2) Mengetahui keikutsertaan kelas ibu hamil; 3) Menganalisis hubungan antara pengetahuan ibu hamil dengan keikutsertaan kelas ibu hamil. Penelitian ini dilakukan dengan desain korelasional dengan pendekatan cross sectional. Jumlah sampel 64 diambil dengan cara sampling jenuh. Pengumpulan data dengan menggunakan kuesioner. Uji statistik menggunakan uji spearman rank. Hasil penelitian menunjukkan ibu hamil memiliki pengetahuan baik sebesar $43,8 \%$ dan ikutserta $68,8 \%$ dalam kelas ibu hamil. Ada hubungan yang signifikan antara variabel pengetahuan dengan keikutsertaan dalam kelas ibu hamil $\left(\rho=0,000, \mathrm{r}_{\mathrm{s}} 0,554\right)$. Kelas ibu hamil merupakan sarana belajar bersama yang perlu diikuti oleh ibu hamil agar memperoleh pengetahuan yang cukup sehingga dapat mencegah komplikasi dan meningkatkan cakupan K4. Disarankan meningkatkan pembentukan kelas ibu hamil agar kehamilan dapat terpantau dan ibu dapat segera mengambil keputusan klinis apabila terjadi resiko.
\end{abstract}

Kata kunci $\quad$ : Pengetahuan, Keikutsertaan, Kelas Ibu Hamil

\section{Pendahuluan}

Kesehatan Ibu dan Anak menjadi target dalam tujuan pembangunan millenium (MDG's), tepatnya pada tujuan 4 dan 5 yaitu menurunkan angka kematian anak dan meningkatkan kesehatan ibu. Program kesehatan ibu dan anak menjadi sangat penting karena ibu dan anak merupakan unsur penting pembangunan (Prasetyawati, 2012). Salah satu mempercepat pencapaian program MDG's, diperlukan upaya percepatan penurunan kematian ibu dan bayi melalui peningkatan pengetahuan dan perubahan perilaku ibu dan keluarga. Dengan peningkatan pengetahuan dan perubahan perilaku ini diharapkan kesadaran terhadap pentingnya kesehatan selama kehamilan menjadi meningkat. Salah satu program yang diselenggarakan oleh kementerian kesehatan untuk mendukung langkah tersebut adalah kelas ibu hamil (KemenKes, 2011).

Kelas ibu hamil adalah salah satu bentuk pendidikan prenatal yang dapat meningkatkan pengetahuan ibu hamil dan perubahan perilaku positif sehingga ibu diharapkan memeriksakan kehamilan dan melahirkan ke tenaga kesehatan. Kelas ibu hamil merupakan sarana belajar bersama yang diikuti oleh ibu hamil agar memperoleh pengetahuan yang cukup sehingga dapat mencegah komplikasi dan meningkatkan cakupan K4. Tujuan diadakannya kelas ibu hamil adalah untuk menambah pengetahuan ibu tentang kesehatan ibu dan anak, sehingga dapat mengurangi terjadinya angka kematian ibu 
dan angka kematian bayi (Depkes RI, 2009; h. 4).

Pertemuan kelas ibu hamil dilakukan 3 kali pertemuan selama hamil atau sesuai dengan hasil kesepakatan fasilitator.Tingkat pengetahuan seseorang biasanya akan mempengaruhi pola pikirnya, baik terhadap kehidupan sosial maupun kesehatan. Seseorang dengan pengetahuan yang baik akan memprioritaskan kesehatan dalam hidupnya dengan partisipasinya dalam mengikuti kelas ibu hamil daripada orang yang pengetahuan yang kurang baik (Depkes RI, 2009; h. 4).

Keterbatasan pengetahuan akan menyulitkan seseorang memahami pentingnya pemeliharaan kesehatan dan perubahan perilaku seseorang ke arah yang menguntungkan kesehatan. Berbagai hal yang memepengaruhi tinggi rendahnya pengetahuan dan partisipasi ibu hamil dalam kelas ibu hamil, diantaranya tingkat pengetahuan ibu hamil dan partisipasi ibu hamil tentang kelas ibu hamil masih banyak yang kurang berpartisipasi dalam kelas ibu hamil. Hal ini dikarenakan waktu pelaksanaan kelas ibu hamil yang kurang efektif dan tempat pelaksanaan ibu hamil. Hambatan dari kurangnya partisipasi dalam kelas ibu hamil dikarenakan ibu hamil tidak tahu adanya kelas ibu hamil di wilayahnya, serta ibu hamil yang bekerja. Adapun dampak bila ibu hamil tidak ikut kelas ibu hamil selama kehamilannya tidak begitu signifikan, akan tetapi ibu hamil tersebut tidak ada perubahan dalam pemahaman, sikap dan perilaku ibu hamil seperti perawatan selama kehamilan, sehingga dalam mempersiapkan persalinannya kurang, serta jika ada resiko pada ibu hamil tersebut tidak langsung terdeteksi oleh tenaga kesehatan (Depkes RI, 2009; h. 3).

Berdasarkan data yang diperoleh dari dinas kesehatan Kota Pekalongan pada tahun 2013 terdapat ibu hamil terbanyak di puskesmas Jenggot sejumlah 957 ibu hamil dari 12 puskesmas yang ada di Kota Pekalongan. Pada perkembangannya kelas ibu hamil di puskesmas Jenggot diadakan satu tahun 4 kali pertemuan secara berturutturut, dimana setiap kelurahan memiliki satu kelompok kelas ibu hamil. Pemanfaatan kelas ibu hamil belum maksimal dilihat dari jumlah kunjungan perkelompok hanya 8-9 ibu hamil setiap pertemuan, hal ini berbanding terbalik dari jumlah ibu hamil yang ada di Puskesmas Jenggot karena kebanyakan peserta yang ikut kelas ibu hamil hanya yang rumahnya dekat dengan tempat pelaksanaan dan waktu pelaksanaan yang kurang efektif yaitu pada jam kerja.

Berdasarkan latar belakang di atas, maka pertanyaan penelitian sebagai berikut: "Apakah ada hubungan antara pengetahuan ibu hamil dengan keikutsertaan Kelas Ibu Hamil di Wilayaha Kerja Puskesmas Jenggot Kota Pekalongan?”.

\section{Metode Penelitian}

Penelitian ini menggunakan kombinasi metode kuantitatif, dimana variabel kuantitatif terdiri dari variabel independent yaitu pengetahuan ibu hamil tentang kelas ibu hamil dan variabel dependent yaitu keikutsertaan kelas ibu hamil. Metode pengumpulan data menggunakan kuesioner.

Penelitian ini dilakukan dengan desain penelitian korelasional dengan pendekatan cross sectional. Populasi dalam penelitian ini adalah seluruh ibu hamil usia kehamilan 4 sampai 36 minggu yang bertempat tinggal di wilayah kerja Puskesmas Jenggot Kota Pekalongan pada Bulan November 2013, Desmber 2013 dan Januari 2014. Teknik pengambilan sampel dalam penelitian ini menggunakan sampling jenuh atau total sampling, yaitu semua anggota populasi digunakan sebagai sampel. Jumlah sampel dalam penelitian ini $64 \mathrm{ibu}$ hamil.

Instrumen Pengumpulan data yang digunakan yaitu instrumen pengumpulan data kuantitatif. Adapun instrumen pengumpulan data kuantitatif dengan menggunakan kuesioner. Kuesioner 
diberikan kepada ibu hamil yang termasuk dalam kriteria inklusi.

Analisis data menggunakan analisa univariat dan bivariat. Analisa univariat yaitu menganalisa tingkat pengetahuan ibu hamil sebagai variabel bebas dengan menggunakan distribusi frekuensi dan prosentase sehingga kategori pengetahuan terbagi menjadi 3, yaitu pengetahuan baik, pengetahuan cukup dan pengetahuan kurang. Yang kedua yaitu menganalisa variabel keikutsertaan kelas ibu hamil menggunakan data yang diperoleh dari pelaksanaan kelas ibu hamil. Analisa Bivariat yaitu analisa yang diduga berhubungan atau berkorelasi, yakni pengetahuan ibu hamil tentang kelas ibu hamil dan keikutsertaan kelas ibu hamil. Uji statistik yang digunakan dalam penelitian ini adalah Uji statistik menggunakan Spearman Rank karena salah satu data berbentuk ordinal atau berjenjang atau rangking, dan rancangan penelitiannya korelasi, selain itu sumber data tidak harus berdistribusi normal (Sugiyono, 2010; h. 224).

\section{Hasil Dan Pembahasan}

A. Analisis Univariat

1) Pengetahuan Ibu Hamil Tentang Kelas Ibu Hamil

Tabel 1. Pengetahuan Ibu Hamil Tentang Kelas Ibu Hamil

\begin{tabular}{clcc}
\hline No & Pengetahuan & $\begin{array}{c}\text { Frekuensi } \\
(\mathbf{f})\end{array}$ & $\begin{array}{c}\text { Presentase } \\
(\mathbf{\%})\end{array}$ \\
\hline 1 & Baik & 28 & 43,8 \\
2 & Cukup & 17 & 26,6 \\
3 & Kurang & 19 & 29,7 \\
\hline & Jumlah & 64 & 100.0 \\
\hline
\end{tabular}

Hasil penelitian menunjukkan bahwa responden yang memiliki pengetahuan baik sebanyak 28 ibu hamil $(43,8 \%)$. responden yang memiliki pengetahuan cukup sebanyak $17 \mathrm{ibu}$ hamil (26,6\%), dan responden yang memiliki pengetahuan kurang sebanyak 19 ibu hamil $(29,7 \%)$.

Dari hasil penelitian, jumlah responden yang memiliki pengetahuan kurang hampir sama dengan jumlah responden yang memiliki pengetahuan cukup. Setelah dilakukan penelitian didapatkan masih kurangnya pengetahuan responden pada kuesioner tentang materi pada pertemuan pertama yaitu perawatan kehamilan dan perubahan tubuh selama kehamilan karena ibu hamil paling banyak pada usia kehamilan trimester 2, sehingga materi yang masih dikuasai adalah pada materi pertemuan ke-2. Hal lain pada kuesioner tentang keikutsertaan suami atau keluarga pada kelas ibu hamil tidak mengikuti, hal ini karena ibu hamil mengetahui bahwa yang ikut hanya ibu hamil saja, tidak melibatkan keluarga.

2) Keikutsertaan Ibu Hamil dalam Kelas Ibu hamil

Tabel 2. Keikutsertaan Ibu Hamil dalam Kelas Ibu hamil

\begin{tabular}{clcc}
\hline No & Partisipasi & $\begin{array}{c}\text { Frekuensi } \\
\text { (f) }\end{array}$ & $\begin{array}{c}\text { Prosent } \\
\text { ase(\%) }\end{array}$ \\
\hline 1 & Ikut serta & 44 & 68,8 \\
2 & Tidak Ikut serta & 20 & 31,3 \\
\hline & Jumlah & 64 & 100,0 \\
\hline
\end{tabular}

Hasil penelitian menunjukkan responden yang ikutserta dalam kelas ibu hamil sebanyak 44 ibu hamil $(68,8 \%)$, responden yang tidak ikutserta dalam kelas ibu hamil sebanyak 20 ibu hamil (31,3\%).

Keikutsertaan ibu hamil tentang kelas ibu hamil di wilayah Puskesmas Jenggot tergolong cukup, hal ini dikarenakan tingkat pengetahuan ibu hamil cenderung baik, serta dari segi pendidikan ibu hamil yang rata-rata berpendidikan SMP sebanyak 28 ibu hamil $(43,8)$. Faktor pengetahuan ibu hamil tentang kelas ibu hamil juga mempengaruhi keikutsertaan kelas ibu hamil, serta lokasi atau tempat pelaksanaan kelas ibu hamil tidak menjadi halangan bagi para ibu hamil 
untuk aktif ikutserta dalam kelas ibu hamil. Ada beberapa faktor lain yaitu mengenai usia ibu hamil bahwa usia tidak menghalangi ibu hamil untuk ikutsreta dalam pelaksanaan kelas ibu hamil, faktor kebiasaan yang dilakukan ibu hamil pada saat ada jadwal kelas ibu hamil responden akan langsung ikutserta dalam kelas ibu hamil tersebut. Ibu hamil yang ikutserta juga dipengaruhi oleh informasi serta pengalaman yang sudah didapatkan sebelumnya, sehingga ibu hamil tersebut ikutserta dalam kelas ibu hamil.

\section{B. Analisis Bivariat}

Dari hasil uji statistik hubungan pengetahuan dengan keikutsertaan kelas ibu hamil dapat diketahui bahwa hasil $\rho$ value sebesar $0,000<\rho=0,05$ sehingga Ho ditolak dan Ha diterima yang artinya adanya hubungan antara pengetahuan dengan keikutsertaan kelas ibu hamil dengan kategori keeratan hubungan 0,554 yang berarti memiliki kekuatan hubungan sedang.

Hasil ini sesuai dengan pendapat (Notoatmodjo, 2003; h.121 dan 143) yang menyatakan bahwa pengetahuan akan menimbulkan kesadaran dan akhirnya menyebabkan orang berperilaku sesuai dengan pengetahuan yang dimilikinya. Keterbatasan pengetahuan akan menyulitkan seseorang memahami pentingnya kemajuan informasi mengenai kesehatan dan perubahan sikap serta perilaku seseorang atau kearah yang menguntungkan.

Seorang ibu hamil yang berpengetahuan baik tentang kelas ibu hamil akan ikutserta dalam kelas ibu hamil. Sedangkan ibu hamil yang berpengetahuan kurang tidak akan ikutserta dalam kelas ibu hamil sehingga dengan adanya hal tersebut perlu dilakukan pemberian informasi tentang pelaksanaan kelas ibu hamil.
Menurut Plumer (dalam Suryawan, 2004:27), dasar pengetahuan yang dimiliki akan mempengaruhi seluruh lingkungan dari masyarakat tersebut. Hal ini membuat masyarakat memahami ataupun tidak terhadap tahap-tahap dan bentuk dari partisipasi yang ada. Pengetahuan merupakan domain penting dalam membentuk suatu tindakan, sedangkan partisipasi diartikan sebagai peranserta aktif dalam kegiatan.

Menurut peneliti tentang hasil penelitian yang telah dilakukan didapatkan kesimpulan bahwa adanya hubungan antara pengetahuan dengan keikutsertaan kelas ibu hamil tersebut akibat adanya tingkat pengetahuan responden yang baik sehingga berpartisipasi dalam kelas ibu hamil dan juga tidak menutup kemungkinan bagi responden yang memiliki tingkat pengetahuan kurang akan tetapi tidak ikut serta karena tidak mendapatkan informasi serta tidak adanya pengalaman sebelumnya. Hal lain yang mempengaruhi ibu tidak ikutserta dalam kelas ibu hamil karena ibu sibuk bekerja serta dari faktor kebiasaan ibu yang menganggap kelas ibu hamil tidak penting bagi kehamilnnya.

Maka dari itu disinilah pentingnya tenaga kesehatan dan fasilitas kesehatan yang ada di Puskesmas Jenggot terutama tokoh masyarakat wilayah tersebut untuk dapat dijadikan sebagai salah satu faktor yang bisa mempengaruhi ibu hamil untuk ikutserta dalam kelas ibu hamil, disamping peran aktif dari masyarakat sendiri untuk mendapatkan informasi tentang kesehatan khususnya tentang kelas ibu hamil.

\section{Simpulan}

Penelitian yang berjudul Hubungan Pengetahuan ibu hamil dengan keikutsertaan kelas ibu hamil di Wilayah Kerja Puskesmas Jenggot Kota Pekalongan dapat disimpulkan sebagai berikut : 
a. Pengetahuan Ibu Hamil tentang Kelas Ibu Hamil Ibu hamil di wilayah kerja Puskesmas Jenggot Kota Pekalongan memiliki pengetahuan yang baik tentang kelas ibu hamil $(43,8 \%)$

b. Keikutsertaan ibu hamil dalam kelas ibu hamil

Ibu hamil di wilayah kerja Puskesmas Jenggot Kota Pekalongan lebih banyak ikutserta $(68,8 \%)$ dalam kelas ibu hamil dibandingkan dengan yang tidak ikutserta $(31,3 \%)$.

c. Hubungan Pengetahuan Ibu hamil dengan Keikutsertaan Kelas Ibu Hamil Ada hubungan yang bermakna antara pengetahuan dengan keikutsertaan kelas ibu hamildengan $(\rho=0,000)$ rs sebesar 0,554 dengan keeratan hubungan yang sedang. Arah hubungannya positif yang artinya semakin tinggi pengetahuan ibu hamil, semakin tinggi keikutsertaannya dalam kelas ibu hamil.

\section{Daftar Pustaka}

[1] Ari Setiawan, Saryono. 2011. Metodelogi Penelitian Kebidanan. Yogyakarta. Penerbit: Nuha Medika

[2] Badriah, Dewi Laelatul. 2009. Metodologi Penelitian Ilmu-ilmu Kesehatan. Bandung. Penerbit: Multazam.

[3] Budiman \& Riyanto, Agus. 2013. Kapita Selekta Kuesioner (Pengetahuan dan Sikap Dalam Penelitian Kesehatan). Jakarta. Penerbit: PT. Salemba Medika

[4] Departemen Kesehatan Republik Indonesia. 2012. Pegangan Fasilator Kelas Ibu Hamil

[5] Departemen Kesehatan Republik Indonesia. 2012. Pedoman Pelaksanaan Kelas Ibu Hamil.

[6] Departemen Kesehatan Republik Indonesia. 2012. Pelatihan Kelas Ibu Kelas Ibu Hamil dan Kelas Ibu Balita
Untuk Petugas Kesehatan Buku Pegangan Pelatih

[7] Departemen Kesehatan Republik Indonesia. 2012. Pelatihan Kelas Ibu Kelas Ibu Hamil dan Kelas Ibu Balita Untuk Petugas Kesehatan Buku Panduan Peserta

[8] Ferdinand, B Tokan. Partisipasi Warga Sekolah dalam Pelaksanaan Program Pendidikan Inklusif di SD NegeriGejayan.2012[Diakses tanggal 03November2013].Didapatdari:http:// eprints.uny.ac.id/7720/com

[9] Hidayat, A. Aziz Alimul. 2010. Metodelogi Penelitian Kebidanan dan Teknik Anallisis Data. Jakarta. Penerbit: Salemba Medika

[10] Notoatmodjo, Soekidjo. 2005. Promosi Kesehatan Teori dan Aplikasi. Jakarta. Penerbit: PT. Rineka Cipta.

[11] Notoatmodjo, Soekidjo. 2012. Promosi Kesehatan dan Perilaku Kesehatan. Jakarta. Penerbit: Rineka Cipta.

[12] Notoatmodjo, Soekidjo. 2005. Metodelogi Penelitian. Jakarta. Penerbit: Rineka Cipta.

[13] Nursalam. 2008. Konsep dan Penerapan Metodologi Penelitian Ilmu Keperawatan Pedoman Skripsi, Tesis dan Instrumen Penelitian Keperawatan. Jakarta. Penerbit: Salemba Medika.

[14] Puji SH, Heru SWN, Nana U. Efektifitas Pelatihan Kelas Ibu Hamil Untuk Meningkatkan Pengetahuan, Sikap, Ketrampilan, dan Kunjungan Antenatal Care. Jawa Timur: Jurnal Kesehatan Masyarakat; 2011 [Diakses tanggal 03 November 2013]. Didapat dari: http://www.suaraforikes.webs.com

[15] Puspitasari, Lia. Gambaran Pelaksanaan Kelas Ibu Hamil di Puskesmas Bangetayu Kota Semarang. Semarang: Jurnal Kesehatan Masyarakat; 2012 
[Diakses tanggal 07 Desember 2013]. Didapat dari: http://www.suaraforikes.webs.com

[16] Ramadhy, Asep Sufyan. 2011. Biologi Reproduksi. Bandung. Penerbit: PT Refika Aditama

[17] Sugiyono. 2010. Statistika Untuk Penelitian. Bandung. Penerbit: Alfabeta

[18] Uswatun Chasanah, Ratifah. Hubungan Pengetahuan Ibu Hamil Tentang Kelas Ibu Hamil Dengan Motivasi Mengikuti Kelas Ibu Hamil Di Puskesmas 2 Mandiraja Kabupaten Banjarnegara. Banjarnegara: Jurnal Ilmiah Kebidanan; 2013 [Diakses tanggal 02 Februari 2014]. Didapat dari: http://www.suaraforikes.webs.com

[19] Wawan, A dan Dewi, M. 2011. Teori dan Pengukuran Pengetahuan, Sikap, dan Perilaku Manusia. Yogyakarta. Penerbit: Nuha Medika.

[20] Yulianti, Yoni. Analisis Partisipasi Masyarakat Dalam Pelaksanaan Program Nasional Pemberdayaan Masyarakat (PNPM) Mandiri Perkotaan Di Kota Solok: Artikel Program Pasca Sarjana Universitas Andalas Padang; 2012 [Diakses tanggal 28 Februari 2013]. Didapat dari: http://pasca.unand.ac.id/id/wpcontent/uploads/2011/09/ANALISISPARTISIPASI-MASYARAKAT.pdf 